\title{
Psychometric Properties of New Subscales of the Ostomy Adjustment Scale: A Cross-Sectional Study
}

Kirsten Lerum Indrebø (1D)

Anny Aasprang ${ }^{2}$

Torill Elin Olsen ${ }^{3}$

John Roger Andersen ${ }^{2,4}$

'Department of Surgery, Førde Central Hospital, Førde, Norway; ${ }^{2}$ Western Norway University of Applied Sciences, Førde, Norway; ${ }^{3}$ Department of Surgery, Haukeland University Hospital, Bergen, Norway; ${ }^{4}$ Centre of Health Research, Førde Hospital Trust, Førde, Norway
This article was published in the following Dove Press journal: Patient Related Outcome Measures

Background: The Ostomy Adjustment Scale (OAS), which consists of an overall sum score along with 34 single-item scores, has been frequently used to measure self-reported adjustment to life with an ostomy. However, it is unknown whether the OAS can be divided into meaningful thematic subscales that may make it easier to administer and to apply in a clinical feedback system. Purpose: The purpose of this study was to specify thematic OAS subscales and evaluate their psychometric properties.

Patients and Methods: A cross-sectional study was conducted with 302 patients across Norway having colostomy, ileostomy, or urostomy. The OAS items were divided into different subscales by expert nurses and patients based on clinical and theoretical considerations. The overall structural validity of this analysis of the OAS was examined using robust confirmatory factor analysis. We evaluated the overall goodness of fit using the root mean square error of approximation (RMSEA), the comparative fit index (CFI) and the TuckerLewis index (TLI). Factor loadings from the confirmatory factor analysis were used to calculate composite reliability values for the new OAS scales.

Results: The OAS was divided into seven subscales. The overall structure validity was acceptable with RMSEA $=0.053(90 \%$ CI, 0.045-0.060), CFI $=0.913$ and TLI $=0.904$. The composite reliability values of all scales were $>0.70$.

Conclusions: The OAS can be divided into seven clinically meaningful subscales with acceptable psychometric properties.

Trial Register: ClinicalTrials.gov Registration Number: NCT03841071. Date 18. February 2019 retrospectively registered.

Keywords: ostomy, adjustment, clinical feedback system, CFS, patient reported outcomes, PRO, factor analysis, outpatient ostomy follow-up

\section{Introduction}

An ostomy may affect quality of life negatively and pose changes physically, psychologically, and socially, and the patients must incorporate new knowledge, skills and psychological changes in everyday life. ${ }^{1-9}$ Studies of several pre- and postoperative follow-up programs and education in ostomy care performed by stoma care nurses (SCNs) have shown that such follow-up and education promote the patient's self-care and adjustment process to life with an ostomy., ${ }^{4,-11}$ Questionnaires such as The Ostomy Adjustment Inventory $23,{ }^{12}$ the Stoma Selfefficacy scale ${ }^{13-15}$ and the Ostomy Adjustment Scale (OAS) ${ }^{16-20}$ has been validated in several countries and used to measure psychosocial adjustment to ostomy.
Correspondence: Kirsten Lerum Indreb Department of Surgery, Førde Central Hospital, Svanehaugvegen I, Førde, 68I2, Norway

Tel +047578392807

Email kirsten.lerum.indrebo@helse-forde. no
Patient Related Outcome Measures 2021:12 65-75

DovePress in $\mathbf{D}$ 
Assessing patient-reported outcomes (PRO) about the patient's adjustment process, before the consultation can prepare the patient, and give SCN information on important issues to discuss during the ostomy follow-up consultation. If, incorporated successfully in clinical practice, a clinical feedback system (CFS) as described here, may improve the quality of the consultations. ${ }^{21}$

However, when monitoring this adjustment process, it is necessary to use validated and well-functioning electronically questionnaires. One such questionnaire, could be the OAS, ${ }^{16}$ based on our experience from using it in patient care. ${ }^{21}$ The OAS is a 34 -item questionnaire measuring the patient's subjective adaptation to the physical, psychological, and social changes that occur after ostomy surgery. It also contains statements about the patient's care of their ostomy, their opinions about the instructions they received about their ostomy, and their feelings about the SCN as well as the surgeon responsible for their ostomy surgery. ${ }^{16}$ All the statements are scored on a Likert scale from 1 (strongly agree) to 6 (strongly disagree); some statements are expressed negatively, and their raw scores are converted by subtracting from 7 before the analysis so that in all cases a higher score indicates better adjustment to the ostomy. The original OAS thus yields a sum score varying from 34 to 204 along with scores from each of the 34 component items. ${ }^{16}$ The reliability of the OAS, as measured by Cronbach's alpha, has been reported to be $0.87,{ }^{16} 0.89,{ }^{19}$ and $0.93^{18}$ in previous studies, and its test-retest correlation coefficients have been reported to be $0.72^{16}$ and $0.69 .{ }^{18}$

Within our CFS, the OAS sum score and single-item scores are currently used as an aid to the patient and SCN in identifying what is most important for them to discuss during their consultation, as the computer displays the patient's answers sorted from lowest adjustment to best adjustment. The sum score provides information about overall adjustment but limited information about the different life areas. On the other hand, single-item OAS scores show in detail the degree of adjustment in each item. Several of the items, however, seem to measure nearly identical themes.

Thus, we think that OAS subscores should be useful. Reporting of subscores from the OAS would make the instrument more useful in CFS, enabling both patient and SCN to discuss different themes more easily. Investigating possible OAS subscales has been tried before, for example, using principal component factor analysis (PCA). ${ }^{16,19}$ However, these studies resulted in different subscales that were unclear, perhaps because of small sample sizes, but also because exploratory approaches such as PCA have methodological limitations. ${ }^{22,23}$ For example, the OAS measures both causal items such as knowledge and skills and effect items such as the patient's overall adjustment to life with an ostomy. Such causalities and effects are different in kind, so the OAS total score may therefore be understood better as a multidimensional index than as a unidimensional construct. ${ }^{24}$ The mixture of causal and effect indicators within the OAS may create problems with using PCA to detect subscales. Cross-loadings between factors may happen easily, leading to confusing findings.

Consequently, purely data-driven methods such as PCA or exploratory factor analysis may therefore be suboptimal for developing and testing multidimensional questionnaires for use in a clinical context. Construction of scales based on theoretical and clinical considerations and then testing them may be a better approach. The purpose of this study was therefore to prespecify thematic OAS subscales and evaluate their psychometric properties.

\section{Patients and Methods \\ Study Design and Patients}

This cross-sectional study investigating further development of the OAS is based on the Norwegian version of the instrument. ${ }^{18,25}$ The study sample included a merged sample of a total of 302 participants, who came from two studies. The first group (158 participants) was recruited from pharmacies in 2010-2011, ${ }^{18}$ and the second group included 144 patients who participated in routine electronic follow-up in the outpatient ostomy clinic at the department of surgery of Førde Central Hospital from April 2018 to January 2020. ${ }^{21}$ Data from the 158 participants recruited in 2010-2011 were plotted by the first author (KLI), and the dataset from 2018 to 2020 was automatically saved in an electronic database when the patient answered the OAS electronically. The study included patients with a newly performed colostomy, ileostomy, or urostomy, and those who had been living with a colostomy, ileostomy, or urostomy for several years. The inclusion criteria were age $>18$ years; experience living with a colostomy, ileostomy, or urostomy for $\geq 3$ months; and ability to speak, read, and write Norwegian.

\section{Ethics Approval and Consent to Participate}

In accordance with the Helsinki Declaration, the study was reviewed and approved by the Regional Committee for Medical Research Ethics in Western Norway (registration numbers 2010/1573 and 2016/255). A paper-based consent 
form was sent together with the invitation to the 3-month outpatient follow-up. Patients who wanted to participate in the study delivered a signed informed consent form when they arrived the consultation. The committee has allowed the older anonymous dataset (registration number 2010/1573) to be used freely. Subjects participating in the study using electronic questionnaires (registration number 2016/255) are entitled to the highest security level possible in Norway to protect patient information. Questionnaires that were answered in paper form, as well as the patient consent forms, are stored in a safe place in the research department of Førde Health Trust. Mary Ellen Olbrisch, the researcher who designed the OAS, provided free permission to use the scale.

\section{Measures}

Sociodemographic variables were recorded as follows: age was a continuous variable; gender was either male or female; marital status was married/cohabiting or living alone/living with children or parents; and education was classified as low ( $<13$ years) or high $(\geq 13$ years). Clinical data included three categorical variables: underlying diagnoses (Ulcerative colitis/Crohn disease, cancer, other diseases, or missing); ostomy type (colostomy, ileostomy, urostomy, or two ostomies); and time since surgery prior to study participation, categorized as $<1$ year or $>1$ year.

\section{Subscale Construction}

The OAS items were divided into subscales based on clinical judgement from expert nurses and a user panel of ostomy patients. The expert nurses were recruited among 11 SCNs from four hospitals in Western Norway and four of them had suggestions on how OAS could be divided into subscales. These SCNs have from 20 to 30 years' clinical experience from outpatient follow-up of ostomy patients, and three of them have a master's degree. They have also participated in writing of a knowledgebased recommendation for follow-up of ostomy patients in Norway, which is about to be translated into English. The user panel was recruited among seven patients who had used the OAS in PRO/CFS. Four patients with ileo, colo or urostomy participated. The research team also consisted of a professor (JRA) with long experience with development and testing of QoL scales, and a SCN who is $\mathrm{PhD}$ candidate (KLI). Previous, the research team has translated OAS into Norwegian and validated the overall summary score in a Norwegian population. ${ }^{18}$

First, each of the four SCNs suggested subscales of the OAS in consideration of the manner and order in which it would be natural to talk about items during a consultation. Second, each SCN's suggestions were sent to all SCNs for new consideration. Third, the subscales were discussed in a meeting between all eleven SCNs and the researchers according to experiences on how it was natural to talk about adjustment in the consultation and according to guidelines and recommendations for follow-up needs of ostomy patients. ${ }^{26,27}$ The suggested OAS subscales were sent to each member of the user panel, and the research team asked for their assessment, especially on the subscales` face validity. The subscale's content was also discussed in a meeting between the user panel and the researchers. Based on the discussions with SCNs and user panel, the final subscales were developed for psychometric testing. Each subscale included from two to nine OAS items.

In this study, we used mean scores (total score divided by number of items) ranging from 1 to 6 . A pragmatic thumb of rule is that scores higher than 4.35 indicate good adjustment, scores from 2.67 to 4.34 indicate some challenges, and scores from 1 to 2.66 indicate low adjustment.

\section{Statistics}

Clinical and sociodemographic data are described as frequency and percentages or means and standard deviation (SD). For each item score and subscale score of the OAS, the mean and SD were calculated. Floor and ceiling effects for each scale were calculated as percentages, and $<15 \%$ indicated possible problems. ${ }^{28}$ The structural validity of the OAS was examined using robust confirmatory factor analysis (CFA) for ordinal data, with weighted least squares and mean and variance (WLSMV) estimation using the R package Lavaan (version 0.6-7). ${ }^{29}$ SPSS version 26 was used for other analyses. Patients who did not complete the full OAS were excluded from the analyses because the WLSMV estimator in Lavaan does not handle missing values. The six OAS response categories were recoded into three categories in the following manner before CFA because several items had response categories with few observations: 1 to $2=1,3$ to $4=2$ and 5 to $6=3 .^{30}$ We evaluated the overall goodness of fit using the root mean square error of approximation (RMSEA), the comparative fit index (CFI), and the Tucker-Lewis index (TLI). Model fit was indicated by RMSEA close to or below 0.06 , and by CFI as well as TLI close to or above $0.95 .^{31,32}$ Factor loadings from the CFA were used to calculate composite reliability (CR) values for the OAS scales, with scores $\geq 0.70$ being considered acceptable. ${ }^{33}$ Factor loadings $<0.4$ were considered poor. 


\section{Results}

The study sample consisted of two merged samples, from which 356 patients received the questionnaire and 302 (84.9\%) completed it. Patient characteristics are presented in Table 1. Those participants who reported two ostomies had colostomy and urostomy.

After theoretical and clinical considerations and discussions, the SCNs and patients (user panel) agreed to divide the original OAS scale into seven subscales. The scales were "daily activities", "knowledge and skills", "self-esteem", "psychological/existential", "health", "health professionals" and "sexuality" (Table 2).

The mean subscale scores ranged from 3.48 to 5.17 , indicating medium to high degrees of adjustment. Subscale floor effects were not observed. However, the subscales "knowledge and skills", "health" and "health professionals" showed noteworthy ceiling effects (Table 2).

Table I Demographic and Pertinent Clinical Characteristics $(\mathrm{N}=302)$

\begin{tabular}{|c|c|}
\hline Variables & Values \\
\hline Age, mean (SD) & $63.3(14.9)$ \\
\hline \multicolumn{2}{|l|}{ Gender, n (\%) } \\
\hline Male & I7I (56.6) \\
\hline Female & $130(43.0)$ \\
\hline \multicolumn{2}{|l|}{ Marital status, n (\%) } \\
\hline Married/cohabiting & $213(70.5)$ \\
\hline Living alone/living with children or parents & $89(29.5)$ \\
\hline \multicolumn{2}{|l|}{ Education, n (\%) } \\
\hline Primary school/senior high school/college & $203(67.2)$ \\
\hline University college/university & $90(28.8)$ \\
\hline Missing & $9(3.0)$ \\
\hline \multicolumn{2}{|l|}{ Underlying diagnoses, n (\%) } \\
\hline Ulcerative colitis/Crohn disease & $95(31.5)$ \\
\hline Cancer & $146(48.3)$ \\
\hline Other diseases & $58(19.2)$ \\
\hline Missing & $3(1.0)$ \\
\hline \multicolumn{2}{|l|}{ Ostomy type, n (\%) } \\
\hline Colostomy & $139(46.0)$ \\
\hline lleostomy & $104(34.4)$ \\
\hline Urostomy & $42(13.9)$ \\
\hline Two ostomies & $7(2.3)$ \\
\hline Missing & $10(3.3)$ \\
\hline \multicolumn{2}{|l|}{ Time since surgery, $\mathrm{n}(\%)$} \\
\hline Less than I y & $104(34.4)$ \\
\hline More than I y & $190(62.9)$ \\
\hline Missing & $8(2.6)$ \\
\hline
\end{tabular}

Note: For gender it is one missing value.
Model fit statistics for the overall OAS structure validity showed an RMSEA $=0.053(90 \%$ CI, 0.045-0.060), $\mathrm{CFI}=0.913$ and TLI $=0.904$. The composite reliability (CR) values of all scales were $>0.70$ (Table 3 ). The pairwise covariance between subscales ranged between 0.12 and 0.48 , which shows that the subscales measure different aspects of the concept of adjustment to ostomy.

\section{Discussion}

The study aimed to construct and test thematic subscales of the OAS for clinical use in outpatient follow-up of ostomy patients. A group of clinicians and patients divided the OAS items into seven subscales, "daily activities", "self-esteem", "psychological/existential", "sexuality", "health", "health professionals" and "knowledge and skills". The model fit for structural validity of this version of the OAS was acceptable. However, some of the items had low factor loadings, although all were $\geq 0.4$. Thus, the model fit was in the lower range for being acceptable. In all subscales, the reliability was acceptable.

A strength of this study is that we have had experience using the OAS as a clinical tool since 2017. Two SCNs conducted patient consultations; therefore, research and clinical practice was close to one another, and their interaction may uncover noteworthy implications for both. The SCNs continually discussed issues about the consultation, for example, how to individualise the way to talk about patients' challenges and how to talk with patients about difficult issues such as body image and sexuality. These discussions may lead to a deeper understanding of the best ways to use the OAS scale in clinic. Clinical involvement gives the researcher a helpful basis for evaluating the results of the statistical analysis, especially how the themes in each subscale can function in practice.

To our best knowledge, this study is the first that have tested the structure validity of the OAS using CFA. Previous studies have performed PCA ${ }^{16,17,19}$ to divide the items mathematically into different subscales. These authors found conflicting results, as several items did not load into any subscales. In the current study, it was found that all items could be included in the subscales. We think this is a strength, as having all items included in the scale gives the patient a broader opportunity to describe potential challenges. On the one hand, low factor loadings for some items indicate those items are less important, so perhaps they should be omitted. However, these items could be very important for some patients. Another consideration is that omission of items would change the instrument, so any study results would 
Table 2 Floor and Ceiling Effects Subscale Scores, and Item Scores of the Ostomy Adjustment Scale $(\mathrm{N}=302)$

\begin{tabular}{|c|c|c|c|c|}
\hline Scales and Items & Floor Effect, \% & Ceiling Effect, \% & $\mathbf{N}(\%)$ & Mean (SD) \\
\hline \multicolumn{5}{|l|}{ Daily activities } \\
\hline Scale score & 0.3 & 0.3 & $258(85.4)$ & $4.18(1.02)$ \\
\hline Item I: I can lead a productive and fulfilling life despite my ostomy & 5.0 & 36.8 & $300(99.7)$ & $4.68(1.4 I)$ \\
\hline Item 2: I think I am leading quite a normal life despite my ostomy & 2.3 & 41.1 & $302(100)$ & $4.95(1.20)$ \\
\hline $\begin{array}{l}\text { Item 3: There are many things I would do if I did not have an } \\
\text { ostomy* }\end{array}$ & 18.9 & 21.5 & $296(98.0)$ & $3.69(1.83)$ \\
\hline Item 4: I feel free to travel where I want despite my ostomy & 8.6 & 35.1 & $299(99.0)$ & $4.41(1.60)$ \\
\hline $\begin{array}{l}\text { Item 5: I have felt comfortable participating in sports and } \\
\text { physical exercise since my ostomy surgery }\end{array}$ & 13.2 & 15.9 & $283(93.7)$ & $3.88(1.62)$ \\
\hline $\begin{array}{l}\text { Item 6: I find that I unnecessarily restrict the range of my } \\
\text { activities because of my ostomy* }\end{array}$ & 7.6 & 24.5 & $302(100)$ & $4.08(1.55)$ \\
\hline $\begin{array}{l}\text { Item 7: I have been better able to work since I had my ostomy } \\
\text { surgery }\end{array}$ & 26.2 & 16.6 & $278(92)$ & $3.44(1.91)$ \\
\hline $\begin{array}{l}\text { Item 32: I feel confident that I can trust my appliance when I am } \\
\text { in public places }\end{array}$ & 9.6 & 32.8 & $298(98.7)$ & $4.48(1.58)$ \\
\hline \multicolumn{5}{|l|}{ Knowledge and skills } \\
\hline Scale score & 1.7 & 44.7 & $296(98.0)$ & $5.16(1.10)$ \\
\hline $\begin{array}{l}\text { Item } 2 \text { I: I feel that I am well-educated about my stoma and } \\
\text { caring for it }\end{array}$ & 4.0 & 63.9 & 300 (99) & $5.29(1.24)$ \\
\hline $\begin{array}{l}\text { Item 22: I am confident that I know the proper methods for } \\
\text { managing my ostomy }\end{array}$ & 3.3 & 46.0 & $297(98)$ & $5.04(1.23)$ \\
\hline \multicolumn{5}{|l|}{ Self-esteem } \\
\hline Scale score & 6.6 & 6.6 & $267(88.4)$ & $4.53(1.01)$ \\
\hline Item 9: At times I lack self-confidence because of my ostomy* & 9.9 & 32.5 & $298(98.7)$ & $4.14(1.73)$ \\
\hline $\begin{array}{l}\text { Item 10: I feel ashamed of my ostomy, as if it were a sign of my } \\
\text { own physical or emotional weakness* }\end{array}$ & 6.6 & 56.6 & $298(98.7)$ & $4.93(1.57)$ \\
\hline Item 12: My self-respect has not suffered because of my ostomy & 7.9 & 46.7 & $299(99)$ & $4.81(1.54)$ \\
\hline $\begin{array}{l}\text { Item I3: I feel somehow "dirty" and "unclean" because of my } \\
\text { ostomy* }\end{array}$ & 6.0 & 51.3 & $298(98.7)$ & $4.84(1.57)$ \\
\hline $\begin{array}{l}\text { Item I4: I leave places early to avoid producing embarrassing } \\
\text { odors in the bathroom* }\end{array}$ & 7.6 & 45.7 & $295(97.6)$ & 4.55 (1.69) \\
\hline Item 15: I feel comfortable with my body, including my stoma & 9.9 & 25.8 & $297(98.3)$ & $4.07(1.66)$ \\
\hline $\begin{array}{l}\text { Item 26: I feel embarrassed by my ostomy, as though it were } \\
\text { something to hide* }\end{array}$ & 7.3 & 44.7 & $302(100)$ & $4.53(1.70)$ \\
\hline $\begin{array}{l}\text { Item 28: I can laugh afterwards about my awkward situations } \\
\text { that happen because of my stoma }\end{array}$ & 10.3 & 34.8 & $285(94.4)$ & $4.46(1.65)$ \\
\hline $\begin{array}{l}\text { Item } 3 I \text { : I think other people would be uncomfortable around } \\
\text { me if they knew about my stoma* }\end{array}$ & 5.0 & 50.3 & $297(100)$ & $4.87(1.50)$ \\
\hline
\end{tabular}

(Continued) 
Table 2 (Continued).

\begin{tabular}{|c|c|c|c|c|}
\hline Scales and Items & Floor Effect, \% & Ceiling Effect, \% & $\mathbf{N}(\%)$ & Mean (SD) \\
\hline \multicolumn{5}{|l|}{ Psychological/existential } \\
\hline Scale score & 3.3 & 0.3 & $252(88.4)$ & $4.28(1.03)$ \\
\hline $\begin{array}{l}\text { Item II: At times I resent my friends who do not have ostomies } \\
\text { or the health problems that lead to ostomy surgery* }\end{array}$ & 41.1 & 14.9 & $297(98.3)$ & $2.80(1.88)$ \\
\hline $\begin{array}{l}\text { Item I6: I feel that I am somehow being punished for something } \\
\text { by having this ostomy* }\end{array}$ & 7.3 & 61.3 & $299(99.0)$ & 4.75 ( 1.79$)$ \\
\hline $\begin{array}{l}\text { Item I7: I get depressed when I realize that I will have this } \\
\text { ostomy for the rest of my life* }\end{array}$ & 8.3 & 50.2 & $295(98.0)$ & $4.75(1.63)$ \\
\hline Item 25: I worry more than I used to about being left alone* & 10.6 & 48.3 & $283(94.0)$ & $4.66(1.74)$ \\
\hline $\begin{array}{l}\text { Item 29: Most of the time, I forget about my ostomy, and am } \\
\text { not aware of it }\end{array}$ & 11.3 & 32.8 & $302(100)$ & $4.36(1.67)$ \\
\hline $\begin{array}{l}\text { Item 33: My ostomy surgery helped me decide what things are } \\
\text { most important in my life }\end{array}$ & 12.9 & 27.5 & $27 \mid(90)$ & $4.27(1.70)$ \\
\hline \multicolumn{5}{|l|}{ Health } \\
\hline Scale score & 0.7 & 28.1 & $285(94.4)$ & $4.99(1.06)$ \\
\hline $\begin{array}{l}\text { Item 23: Since I have had my surgery, I feel I am more likely to } \\
\text { get sick than other people* }\end{array}$ & 5.3 & 52.6 & $298(99)$ & $4.91(1.50)$ \\
\hline $\begin{array}{l}\text { Item 24: I find myself worrying that my surgery did not really } \\
\text { cure my health problems* }\end{array}$ & 5.6 & 54.0 & $293(97)$ & $4.96(1.49)$ \\
\hline $\begin{array}{l}\text { Item 34: My ostomy reminds me how fortunate I am to have } \\
\text { received good medical care }\end{array}$ & 4.3 & 54.0 & $296(98)$ & $5.10(1.31)$ \\
\hline \multicolumn{5}{|l|}{ Health professionals } \\
\hline Scale score & 0.7 & 46.7 & $282(93.4)$ & $5.17(1.07)$ \\
\hline $\begin{array}{l}\text { Item I8: I can discuss even the most embarrassing aspects of my } \\
\text { ostomy with my doctor }\end{array}$ & 2.6 & 67.2 & $289(96)$ & $5.3(1.30)$ \\
\hline $\begin{array}{l}\text { Item 19: I feel like a complainer when I have to contact my } \\
\text { doctor or ET about my ostomy* }\end{array}$ & 7.3 & 61.9 & $295(98)$ & $5.00(1.62)$ \\
\hline $\begin{array}{l}\text { Item 20: I avoid telling my doctor about changes in my stoma } \\
\text { and its functioning* }\end{array}$ & 2.6 & 67.2 & $233(77.2)$ & $5.30(1.30)$ \\
\hline \multicolumn{5}{|l|}{ Sexuality } \\
\hline Scale score & 9.6 & 3.3 & $257(85.1)$ & $3.48(1.44)$ \\
\hline $\begin{array}{l}\text { Item 8: I am more able to enjoy sexual activities because of } \\
\text { improved health since having ostomy surgery }\end{array}$ & 8.0 & 33.1 & $257(85)$ & $3.03(1.88)$ \\
\hline $\begin{array}{l}\text { Item 27: I feel I am not as sexually attractive as I used to be } \\
\text { because of my stoma* }\end{array}$ & 27.0 & 17.2 & $264(87)$ & $3.33(1.93)$ \\
\hline $\begin{array}{l}\text { Item 30: I worry about embarrassing accidents happening in the } \\
\text { course of normal sexual activity* }\end{array}$ & 14.6 & 25.2 & $246(82)$ & $3.91(1.89)$ \\
\hline
\end{tabular}

Note: Negative statements were inverted to a positive scale (marked with*). 
Table 3 Confirmatory Factor Analysis and Composite Reliability Values of the Ostomy Adjustment Scale Measures

\begin{tabular}{|c|c|}
\hline & Stand Coeff. \\
\hline Cov. (Daily activities, Self-esteem) & 0.48 \\
\hline Cov. (Daily activities, Psychological/existential) & 0.30 \\
\hline Cov. (Daily activities, Health) & 0.40 \\
\hline Cov. (Daily activities, Sexuality) & 0.30 \\
\hline Cov. (Daily activities, Knowledge skills) & 0.37 \\
\hline Cov. (Daily activities, Health professionals) & 0.25 \\
\hline Cov. (Self-esteem, Psychological/existential) & 0.30 \\
\hline Cov. (Self-esteem, Health) & 0.43 \\
\hline Cov. (Self-esteem, Sexuality) & 0.24 \\
\hline Cov. (Self-esteem, Knowledge skills) & 0.33 \\
\hline Cov. (Self-esteem, Health professionals) & 0.30 \\
\hline Cov. (Psychological/existential, Health) & 0.29 \\
\hline Cov. (Psychological/existential, Sexuality) & 0.17 \\
\hline Cov. (Psychological/existential, Knowledge skills) & 0.21 \\
\hline Cov. (Psychological/existential, Health professionals) & 0.18 \\
\hline Cov. (Health, Sexuality) & 0.18 \\
\hline Cov. (Health,Knowledge and skills) & 0.40 \\
\hline Cov. (Health, Health professionals) & 0.31 \\
\hline Cov. (Sexuality, Knowledge skills) & 0.17 \\
\hline Cov. (Sexuality, Health professionals) & 0.12 \\
\hline Cov. (Knowledge skills, Health professionals) & 0.22 \\
\hline \multicolumn{2}{|l|}{ Daily activities (composite reliability $=0.87$ ) } \\
\hline Item I: I can lead a productive and fulfilling life despite my ostomy & 0.86 \\
\hline Item 2: I think I am leading quite a normal life despite my ostomy & 0.77 \\
\hline Item 3: There are many things I would do if I did not have an ostomy* & 0.74 \\
\hline Item 4: I feel free to travel where I want despite my ostomy & 0.65 \\
\hline Item 5: I have felt comfortable participating in sports and physical exercise since my ostomy surgery & 0.71 \\
\hline Item 6: I find that I unnecessarily restrict the range of my activities because of my ostomy* & 0.45 \\
\hline Item 7: I have been better able to work since I had my ostomy surgery & 0.53 \\
\hline Item 32: I feel confident that I can trust my appliance when I am in public places & 0.64 \\
\hline \multicolumn{2}{|l|}{ Knowledge and skills (composite reliability $=0.80$ ) } \\
\hline Item 2I: I feel that I am well-educated about my stoma and caring for it & 0.87 \\
\hline Item 22: I am confident that I know the proper methods for managing my ostomy & 0.76 \\
\hline
\end{tabular}


Table 3 (Continued).

\begin{tabular}{|c|c|}
\hline & Stand Coeff. \\
\hline \multicolumn{2}{|l|}{ Self-esteem (composite reliability $=\mathbf{0 . 8 8})$} \\
\hline Item 9: At times I lack self-confidence because of my ostomy* & 0.70 \\
\hline Item I0: I feel ashamed of my ostomy, as if it were a sign of my own physical or emotional weakness* & 0.74 \\
\hline Item I2: My self-respect has not suffered because of my ostomy & 0.54 \\
\hline Item I3: I feel somehow "dirty" and "unclean" because of my ostomy* & 0.87 \\
\hline Item 14: I leave places early to avoid producing embarrassing odors in the bathroom* & 0.60 \\
\hline Item 15: I feel comfortable with my body, including my stoma & 0.56 \\
\hline Item 26: I feel embarrassed by my ostomy, as though it were something to hide* & 0.74 \\
\hline Item 28: I can laugh afterwards about my awkward situations that happen because of my stoma & $0.4 \mathrm{I}$ \\
\hline Item 3I: I think other people would be uncomfortable around me if they knew about my stoma* & 0.74 \\
\hline \multicolumn{2}{|l|}{ Existential/psychological (composite reliability $=\mathbf{0 . 8 0}$ ) } \\
\hline Item I I: At times I resent my friends who do not have ostomies or the health problems that lead to ostomy surgery* & 0.46 \\
\hline Item I6: I feel that I am somehow being punished for something by having this ostomy* & 0.63 \\
\hline Item 17: I get depressed when I realize that I will have this ostomy for the rest of my life* & 0.88 \\
\hline Item 25: I worry more than I used to about being left alone* & 0.76 \\
\hline Item 29: Most of the time, I forget about my ostomy, and am not aware of it & 0.61 \\
\hline Item 33: My ostomy surgery helped me decide what things are most important in my life & 0.42 \\
\hline \multicolumn{2}{|l|}{ Health $($ composite reliability $=\mathbf{0 . 7 2})$} \\
\hline Item 23: Since I have had my surgery, I feel I am more likely to get sick than other people* & 0.70 \\
\hline Item 24: I find myself worrying that my surgery did not really cure my health problems* & 0.77 \\
\hline Item 34: My ostomy reminds me how fortunate I am to have received good medical care & 0.56 \\
\hline \multicolumn{2}{|l|}{ Health Professionals (composite reliability $=\mathbf{0 . 7 8}$ ) } \\
\hline Item I8: I can discuss even the most embarrassing aspects of my ostomy with my doctor & 0.51 \\
\hline Item 19: I feel like a complainer when I have to contact my doctor or ET about my ostomy* & 0.84 \\
\hline Item 20: I avoid telling my doctor about changes in my stoma and its functioning* & 0.84 \\
\hline \multicolumn{2}{|l|}{ Sexuality (composite reliability $=0.74)$} \\
\hline Item 8: I am more able to enjoy sexual activities because of improved health since having ostomy surgery & 0.46 \\
\hline Item 27: I feel I am not as sexually attractive as I used to be because of my stoma* & 0.68 \\
\hline Item 30: I worry about embarrassing accidents happening in the course of normal sexual activity* & 0.91 \\
\hline
\end{tabular}

Note: Negative statements were inverted to a positive scale (marked with*).

not be directly comparable with those from studies using the full validated version of the OAS scale.

A methodological limitation is that the robust factor analysis we applied does not handle missing data, so our analysis had to omit answers that were not fully completed. Though we recognize the limitations of robust factor analysis, we think it is a correct analysis method when the data are skewed and ordinal such as in this study. 
Because purely data-driven statistical approaches are unable to account for the mix of causal and effect indicators within the OAS scale, we believe clinical consideration of the subscales must indeed precede the statistical analysis. Another issue may be that in the sample, 13.9\% had an urostomy, and those may have some other adjustment challenges than those with fecal ostomy, for example they have no noise and less diet challenges, but rather challenges related to urinary tract infections. This may affect the results in a research context. However, in a clinical consultation, the patient's ostomy type is known. Finally, we had a modest sample size. According to rules of thumbs based on Monte Caro simulations, a sample size of $\geq 200$ with $5-10$ cases per parameter estimate may be adequate in a CFA. ${ }^{34}$ However, such simplified rules should be taken with cation. Thus, further research should be conducted to investigate the robustness of our findings, especially stratified analysis in patients with different types of ostomies.

Table 2 shows that the subscales "knowledge and skills", "health professionals" and "health" have high ceiling effects. The sample consists of one-third having ostomy for $<1$ year and two-thirds having it for $>1$ year. The results may reflect that the patients feel well educated in practical skills and more theoretical themes such as diet. The high ceiling effect in the subscales "health" and "health professionals" may indicate that the patients judge both their health and the health care as good, but alternatively they may find it difficult to evaluate the clinician negatively. The mean scores in the subscale "sexuality" are lower than in the other subscales, which may indicate that sexuality remains a challenge after ostomy surgery as shown in several other studies. $4,5,35$

\section{Implications for Practice}

The study's results open up at least two ways to use the OAS scale in clinical practice. In both alternatives, we can assess the sum scores of the whole scale and scores for the single items.

Alternative 1, use of the OAS as a single scale: This approach shows the items ranked according to scores and points towards issues important to the patient, and it promotes an in-depth discussion about those topics. On the other hand, the consultation may be somewhat unstructured because some concepts can appear several times in similar items.

Alternative 2, use of the thematic OAS subscales from the current study, where the lowest score in each subscale appears first on the computer screen: The model may lead to a more systematically conducted consultation than in model 1. This version could be based on the patient's preferences, where the greatest challenges seen by the patient in each subscale could be discussed first. The mean score on the subscales may also aid the consultation and can be used in research.

In summary, both ways to conduct the consultation have advantages and disadvantages. Today we use the first alternative, and when using this alternative some items belonging to the same themes may appear several times during the consultation. Using subscales that include all OAS items may result in more systematic consultations without changing the content of the original OAS. Clinical experience with CFS using the OAS with reporting that includes thematic subscales, and to compare this with use with reporting only of the overall sum and single-item scores is necessary. We also need to consider whether we might reduce the patient burden by having fewer items in each subscale, for example, by omitting items with low factor loadings. Both the proposed ways of using the scale are possible, so having a choice could help the follow-up being patient-centred. The opportunity to discuss themes instead of only items may make the second model, with use of subscales, more advantageous for electronic follow-up of ostomy patients.

\section{Conclusion}

Clinical judgement and psychometric tests suggest that the OAS can be divided into seven subscales. In clinic practice, both the single items version and the version with subscales may promote patient-centred follow-up. It is a need for both quantitative and qualitative studies of use of the OAS, electronically tailored into subscales, in clinical follow-up of ostomy patients.

\section{Abbreviations}

CFS, clinical feedback system; CFA, confirmatory factor analysis; ET, enterostomal therapist; HRQoL, healthrelated quality of life; OAS, Ostomy Adjustment Scale; PCA, principal component analysis; ROM, routine outcome measures; SCN, stoma care nurse; SF-36, short form 36; WLSMV, weighted least squares and mean and variance.

\section{Data Sharing Statement}

The dataset generated during this study will not be publicly available as the patient consent and approval from the Regional Committee for Medical Research Ethics prevents 
sharing of individual patient-level data in public repositories. However, the data will be available from the corresponding author upon reasonable request.

\section{Acknowledgments}

We thank the patients in the user panel and the expert nurses for all help during the design of the study. We also thank Andrew Athan Mc Aleavey, specialist in statistics and scale development for valuable advises.

\section{Author Contributions}

All authors contributed to data analysis, drafting or revising the article, have agreed on the journal to which the article will be submitted, gave final approval of the version to be published, and agree to be accountable for all aspects of the work.

\section{Funding}

The study is funded by the Norwegian Nursing Council to cover the salary of the $\mathrm{PhD}$ student for 4 years $(75 \%$ payment each year). The research group "Folkehelse, Livsstil og Overvekt" of the Research Department, Førde Health Trust, covers the operating costs for the study for 4 years.

\section{Disclosure}

The authors declare that they have no competing interests in this work.

\section{References}

1. Claessens I, Probert R, Tielemans C, et al. The Ostomy Life Study: the everyday challenges faced by people living with a stoma in a snapshot. Gastrointestinal Nurs. 2015;13(5):18-25. doi:10.12968/ gasn.2015.13.5.18

2. Lopes A, Decesaro M. The adjustments experienced by persons with an ostomy: an integrative review of the literature. In: King of Prussia. Vol. 60. HMP Communications:2014;34-42. https://pubmed.ncbi.nlm. nih.gov/25299816.

3. Fingren J, Lindholm E, Petersen C, Hallen A-M, Carlsson E, A prospective, explorative study to assess adjustment 1 year after ostomy surgery among Swedish patients. J Ostomy Wound Manage. 2018;64(6):12-22. doi:10.25270/owm.2018.6.1222

4. Ayaz-Alkaya S. Overview of psychosocial problems in individuals with stoma: a review of literature. Int Wound J. 2018;16(1):243-249. doi:10.1111/iwj.13018

5. Pia N, Ursula D, Thyra L, Jörgen R, Ulf G, Karin S. Quality of life in patients with a permanent stoma after rectal cancer surgery. Qual Life Res. 2017;26(1):55-64. doi:10.1007/s11136-016-1367-6

6. Villa G, Manara DF, Brancato T, et al. Life with a urostomy: a phenomenological study. Appl Nurs Res. 2018;39:46-52. doi:10.1016/j.apnr.2017.10.005

7. Giordano V, Nicolotti M, Corvese F, Vellone E, Alvaro R, Villa G. Describing self-care and its associated variables in ostomy patients. J Adv Nurs. 2020;76(11):2982-2992. doi:10.1111/jan.14499
8. Vonk-Klaassen SM, de Vocht HM, den Ouden MEM, Eddes EH, Schuurmans MJ. Ostomy-related problems and their impact on quality of life of colorectal cancer ostomates: a systematic review. Qual Life Res. 2015;25(1):125-133. doi:10.1007/s11136-015-1050-3

9. Lim SH, Chan SWC, He H-G. Patients' experiences of performing self-care of stomas in the initial postoperative period. Cancer Nurs. 2015;38(3):185-193. doi:10.1097/ncc.0000000000000158

10. Cheng F, Meng A-F, Yang L-F, Zhang Y-N. The correlation between ostomy knowledge and self-care ability with psychosocial adjustment in Chinese patients with a permanent colostomy: a descriptive study. Ostomy Wound Manage. 2013;59(7):35-38.

11. Villa G, Mannarini M, Della Giovanna G, Marzo E, Manara DF, Vellone E. A literature review about self-care on ostomy patients and their caregivers. Int J Urol Nurs. 2019;13(2):75-80. doi:10.1111/ ijun. 12182

12. Simmons KL, Smith JA, Maekawa A. Development and psychometric evaluation of the ostomy adjustment inventory-23. $J$ Wound Ostomy Continence Nurs. 2009;36(1):69-76. doi:10.1097/ WON.0b013e3181919b7d

13. Bekkers MJTM, Van Knippenberg FCE, Van Den Borne HW, Van Berge-henegouwen GP. Prospective evaluation of psychosocial adaption to stoma surgery: the role of self-efficacy. 1996;58(2):183-191.

14. Wu HK-M, Chau JP-C, Twinn S. Self-efficacy and quality of life among stoma patients in Hong Kong. Cancer Nurs. 2007;30 (3):186-193. doi:10.1097/01.Ncc.0000270704.34296.86

15. Karaçay P, Toğluk Yigitoglu E, Karadağ AJI. The validity and reliability of the Stoma Self-Efficacy Scale: a methodological study. International Journal of Nursing Practice. 2020;26(6):e12840. doi:10.1111/ijn.12840

16. Olbrisch ME. Development and validation of the Ostomy Adjustment Scale. J Rehabilit Psychol. 1983;28(1):3. doi:10.1037/h0090996

17. Zhang J-E, Wong FKY, Zheng M-C, Hu A-L, Zhang H-Q. Psychometric evaluation of the ostomy adjustment scale in Chinese cancer patients with colostomies. Cancer Nurs. 2015;38(5):395-405. doi:10.1097/NCC.0000000000000213

18. Indrebø KL, Andersen JR, Natvig GKJ. The Ostomy Adjustment Scale: translation into Norwegian language with validation and reliability testing. J Wound Ostomy Continence Nurs. 2014;41 (4):357-364. doi:10.1186/s12955-019-1261-3

19. Burckhardt CS, Eisenberg MG. The ostomy adjustment scale: further evidence of reliability and validity. Rehabil Psychol. 1990;35 (3):149-155. doi:10.1037/h0079056

20. Brydolf M, Berndtsson I, Lindholm E, Berglund B. Evaluation of a Swedish version of the Ostomy Adjustment Scale. Scand J Caring Sci. 1994;8(3):179-183. doi:10.1111/j.1471-6712.1994.tb00019.x

21. Indrebø KL, Aasprang A, Olsen TE, Andersen JR. A new model of patient-reported outcome monitoring with a clinical feedback system in ostomy care: rationale, description and evaluation protocol. Health Qual Life Outcomes. 2020;18(1):1-8. doi:10.1186/s12955-019-1261-3

22. Fayers PM, Hand DJ. Factor analysis, causal indicators and quality of life. Qual Life Res. 1997;6(2):139-150. doi:10.1023/A:1026490117121.

23. Marsh HW, Morin AJ, Parker PD, Kaur G. Exploratory structural equation modeling: an integration of the best features of exploratory and confirmatory factor analysis. J Annual Rev Clin Psychol. 2014;10:85-110. doi:10.1146/annurev-clinpsy-032813-153700

24. Fayers PM, Machin D. Quality of Life: The Assessment, Analysis and Interpretation of Patient-Reported Outcomes. 2nd ed. Chichester: John Wiley; 2007.

25. Indrebø KL, Natvig GK, Andersen JR, Cross-sectional A. Study to determine whether adjustment to an ostomy can predict health-related and/or overall quality of life. Ostomy Wound Manage. 2016;62 (10):50-59.

26. Zulkowski K, Ayello E, Stelton S. WCET International Ostomy Guideline. J Osborne Park Austr. 2014. Available from: https:// www.wcetn.org/assets/Publications/wcet_april-june_2014f\%20iog\% 20recommandations.pdf. 
27. Olsen T, Indrebø KL, Dagsland V, Lindam A, Skogmo LG Faglig anbefaling for oppfølging av stomiopererte. 2020. Available from: https:/www.nsf.no/fg/stomi-og-kontinenssykepleiere/nyheter/norskfaglig-anbefaling-oppfolging-av-stomiopererte. Accessed March 3, 2021.

28. McHorney CA, Tarlov AR. Individual-patient monitoring in clinical practice: are available health status surveys adequate? Qual Life Res. 1995;4(4):293-307. doi:10.1007/bf01593882

29. Rosseel Y. Lavaan: an R package for structural equation modeling and more. Version 0.5-12 (BETA). J Statistical Software. 2012;48 (2):1-36. doi:10.18637/jss.v048.i02

30. DiStefano C, Shi D, Morgan GB. Collapsing categories is often more advantageous than modeling sparse data: investigations in the CFA framework. J Struct Equat Modeling. 2020;1-13. doi:10.1080/ 10705511.2020.1803073

31. Brown TA. Confirmatory Factor Analysis for Applied Research. Guilford publications; 2015; doi:10.5860/choice.44-2769
32. Hu L, Bentler PM. Cutoff criteria for fit indexes in covariance structure analysis: conventional criteria versus new alternatives. J Structural Equation Modeling. 1999;6(1):1-55. doi:10.1080/ 10705519909540118

33. Raykov T. Estimation of composite reliability for congeneric measures. J Appl Psychol Measurement. 1997;21(2):173-184. doi:10.1177/01466216970212006

34. Myers ND, Ahn S, Jin Y. Sample size and power estimates for a confirmatory factor analytic model in exercise and sport. Res Q Exerc Sport. 2011;82(3):412-423. doi:10.1080/ 02701367.2011.10599773

35. Rutherford C, Müller F, Faiz N, King MT, White K. Patient-reported outcomes and experiences from the perspective of colorectal cancer survivors: meta-synthesis of qualitative studies. J PatientReported Outcomes. 2020;4(1):27. doi:10.1186/s41687-020-00195-9

\section{Publish your work in this journal}

Patient Related Outcome Measures is an international, peer-reviewed, open access journal focusing on treatment outcomes specifically relevant to patients. All aspects of patient care are addressed within the journal and practitioners from all disciplines are invited to submit their work as well as healthcare researchers and patient support groups.
The manuscript management system is completely online and includes a very quick and fair peer-review system. Visit http://www. dovepress.com/testimonials.php to read real quotes from published authors. 